\title{
Activity in the Ventral Medial Prefrontal Cortex Is Necessary for the Therapeutic Effects of Extinction in Rats
}

\author{
Elizabeth A. Fucich, ${ }^{1}$ Denisse Paredes, ${ }^{1}{ }^{\oplus}$ Madeleine 0. Saunders, ${ }^{1}$ and $\odot$ David A. Morilak ${ }^{1,2}$ \\ ${ }^{1}$ Department of Pharmacology and Center for Biomedical Neuroscience, University of Texas Health Science Center at San Antonio, San Antonio, Texas, \\ 78229, and ${ }^{2}$ South Texas Veterans Health Care System, San Antonio, Texas 78229
}

\begin{abstract}
Poor response and high relapse rates remain problematic in the treatment of stress-related psychiatric disorders such as depression and post-traumatic stress disorder. Although mechanisms of pharmacotherapies are intensely studied, little is known about mechanisms of behavioral therapy that could inform improved treatments. We have previously demonstrated the therapeutic effects of extinction learning as a behavioral intervention modeling exposure therapy in rats. In the present study, we tested the hypothesis that activity in the ventral medial prefrontal cortex (vmPFC) during extinction is necessary for its therapeutic effects. The inhibitory Gi-coupled designer receptor exclusively activated by designer drug CaMKII $\alpha$-hM4Di was expressed in vmPFC before administering chronic unpredictable stress (CUS). vmPFC projection neurons were then inhibited during extinction treatment by administering clozapine- $N$-oxide. Coping behavior and cognitive flexibility were assessed $24 \mathrm{~h}$ later on the shock-probe defensive burying test and attentional set-shifting test, respectively. Replicating previous results, extinction reversed the CUS-induced deficits in coping behavior and cognitive flexibility. Inhibiting vmPFC during extinction blocked these therapeutic effects. Further, increasing vmPFC activity with the excitatory Gq-coupled designer receptor exclusively activated by designer drug hM3Dq $24 \mathrm{~h}$ before testing was sufficient to reverse the CUS-induced deficits. CUS reduced mPFC responsivity, assessed by measuring afferentevoked field potentials in the $\mathrm{mPFC}$, and this reduction was reversed by extinction treatment $24 \mathrm{~h}$ before testing. These results demonstrate the necessity of vmPFC activity in the therapeutic effects of extinction as a model of exposure therapy, and suggest that increased vmPFC activity induced by extinction is sufficient to produce lasting plastic changes that underlie its beneficial effects.
\end{abstract}

Key words: behavioral therapy; cognitive flexibility; coping behavior; extinction; medial prefrontal cortex; stress

Significance Statement

Stress-related psychiatric disorders remain poorly treated. Psychotherapies can be effective, but their mechanisms remain unknown, hindering progress toward improved treatment. We used a rat model of behavioral therapy to identify potential targets for enhancing treatment. Fear extinction as a therapeutic behavioral intervention reversed stress-induced cognitive dysfunction and passive coping in rats, modeling components of stress-related psychiatric disease. Extinction also reversed stress-induced attenuation of mPFC responsivity. The therapeutic effects were prevented by blocking activity of glutamatergic neurons in the mPFC during extinction, and were mimicked by inducing activity in lieu of extinction. Thus, activity and plasticity in the mPFC underlie the beneficial effects of extinction on cognitive flexibility and coping behavior compromised by stress, and could be targets to enhance behavioral therapy.

\section{Introduction}

Stress is a risk factor for psychiatric illnesses, such as posttraumatic stress disorder and depression. Cognitive behavioral

Received March 6, 2017; revised Dec. 12, 2017; accepted Dec. 25, 2017.

Author contributions: E.A.F., D.P., and D.A.M. designed research; E.A.F., D.P., and M.O.S. performed research; E.A.F., D.P., M.O.S., and D.A.M. analyzed data; E.A.F., D.P., M.O.S., and D.A.M. wrote the paper.

This work was supported by National Institute of Mental Health Research Grants MH072672 and MH053851, National Institutes of Health T32 Training Grant NS082145, National Center for Advancing Translational Sciences Fellowship Grant TL1 TR001119, U.S. Department of Veterans Affairs Biomedical Laboratory Research and Development Program Merit Award 1101BX003512, and William and Ella Owens Medical Research Foundation, none of which had any role in study design, data collection, analysis or interpretation, nor in the preparation or decision to submit this paper for publication. The contents of this paper do not represent the views of the Department of Veterans Affairs or the U.S. Government. We thank Lauren Hatherall, Jeri Silva, Suphada Lertphinyowong, and Kelly Hohl for technical assistance. therapies (e.g., exposure therapy) improve many symptom dimensions, such as maladaptive coping and cognitive dysfunction, shared by these comorbid illnesses. However, as with current pharmacotherapies, the efficacy of behavioral psychotherapy is limited (de Kleine et al., 2013), and little is known about its mech-

D.A.M. serves on a Psychopharmacology advisory board for H. Lundbeck A/S and receives research funding from Lundbeck Research USA. These activities have no relation to the work presented in this paper. The remaining authors declare no competing financial interests.

Correspondence should be addressed to Dr. David A. Morilak, Department of Pharmacology, Mail Code 7764, University of Texas Health Science Center, 7703 Floyd Curl Drive, San Antonio, TX 78229-3900. E-mail: Morilak@uthscsa.edu.

D0I:10.1523/JNEUROSCI.0635-17.2017

Copyright $\odot 2018$ the authors $\quad 0270-6474 / 18 / 381408-10 \$ 15.00 / 0$ 
anisms, the understanding of which could guide the development of more effective treatments.

Procedurally, fear extinction learning is similar to exposure therapy, where patients are repeatedly exposed in a safe environment to stimuli previously associated with danger until hyperarousal decreases (Foa and Meadows, 1997). For fear extinction, rats are conditioned to fear an innocuous cue, such as a tone by pairing it with a shock. Then, repeated exposure in a different context to tones without shock decreases fear behavior evoked by the tone (Quirk et al., 2006). In addition to these similarities (McNally, 2007; Hofmann, 2008), we previously demonstrated the therapeutic effectiveness of extinction to reverse stressinduced coping and cognitive flexibility deficits in rats as a preclinical model of behavioral therapy (Fucich et al., 2016). This model can thus be used to investigate novel mechanisms of treatment.

Neuroimaging data have provided insight into how behavioral therapy might impact neural function. Increased activity in the medial prefrontal cortex (mPFC) has been observed after psychotherapy (Ritchey et al., 2011; Yoshimura et al., 2014; Straub et al., 2015). This is in contrast to the hypoactivity seen in stress-related psychiatric disorders (Sheline, 2003; Rogers et al., 2004). Indeed, remission from depression has been associated with a normalization of prefrontal hypofunction, reflecting a restoration of cortical control of hyper-reactive limbic structures, the activity of which is reduced with remission (for review, see Salerian and Altar, 2012). These findings suggest that mPFC activation may play a role in the efficacy of psychotherapy, and in restoring function in this brain region, which mediates cognitive flexibility and also regulates adaptive coping behavior via descending projections to limbic areas.

Similarly, mPFC activation is seen after extinction in rats, and activity of limbic targets of the mPFC is altered as well (SotresBayon et al., 2004). Activity of glutamatergic projection neurons in the ventral mPFC (vmPFC) (i.e., the infralimbic [IL] cortex) specifically are required for extinction memory (Do-Monte et al., 2015), and extinction-induced activity of these neurons could play a role in not only inducing plasticity in the vmPFC but also in the modulation of limbic activity that is seen with extinction. Thus, we hypothesized that activation of glutamatergic neurons in vmPFC that project to downstream targets may be important for the beneficial effects of fear extinction as a model of behavioral therapy. We used Gi-coupled designer receptors exclusively activated by designer drug (DREADDs) to test the necessity of glutamatergic neuron activity in the vmPFC during fear extinction for its beneficial effects in reversing coping behavior and cognitive flexibility that have been compromised by chronic stress. We then tested the sufficiency of increasing vmPFC activity alone for improving stress-compromised behaviors using a Gq-coupled DREADD in place of behavioral intervention. We have previously reported that, along with deficits in cognitive flexibility mediated in the vmPFC, chronic stress attenuates the response of vmPFC to excitatory afferent stimulation (Jett et al., 2017), perhaps related to stress-induced structural changes ( $\mathrm{Li}$ ston et al., 2006). Thus, we also examined the functional impact of chronic stress and extinction on afferent-evoked response of the vmPFC. We hypothesized that extinction would induce plasticity in the vmPFC that opposes or counteracts the dysfunction induced by chronic stress, as a potential mechanism underlying its beneficial behavioral effects. Portions of this work have been presented in meeting abstracts (Fucich et al., 2015; Morilak et al., 2016).
Table 1. CUS schedule, including timing of other experimental treatments

\begin{tabular}{ll}
\hline Day & Treatment \\
\hline Day -1 & Habituation to fear conditioning contexts \\
Day 0 & Fear conditioning (extinction groups only) \\
Day 1 & Restraint \\
Day 2 & Shaking/crowding \\
Day 3 & Social defeat \\
Day 4 & Warm swim \\
Day 5 & Wet bedding \\
Day 6 & Social defeat \\
Day 7 & Shaking/crowding \\
Day 8 & Footshock \\
Day 9 & Warm swim \\
Day 10 & Social defeat \\
Day 11 & Footshock (begin food restriction for AST) \\
Day 12 & Tail pinch \\
Day 13 & Cold swim \\
Day 14 & Cold stress \\
Day 15 & AST habituation \\
Day 16 & AST training \\
Day 17 & CN0; extinction or tone control treatment \\
Day 18 & SPDB or AST testing \\
\hline
\end{tabular}

\section{Materials and Methods}

Animals. A total of 208 adult male Sprague Dawley rats (Envigo, RRID: RGD_737903), 225-249 g, were singly housed on a 12/12 h light/dark cycle (lights on at $0700 \mathrm{~h}$ ) with food and water ad libitum. For social defeat, 12 male Long-Evans rats, 400-450 g (Charles River, RRID: RGD_2308852), were pair-housed with ovariectomized females in large cages $(63 \times 63 \times 40 \mathrm{~cm})$. Experiments were conducted during the light phase. All procedures were in accordance with National Institutes of Health guidelines and approved by the University of Texas Health Science Center at San Antonio Institutional Animal Care and Use Committee.

Viral delivery and targeted expression of DREADDs. Rats received bilateral stereotaxic microinjections targeting the IL (from bregma: anteroposterior 2.9 , mediolateral \pm 2.8 , dorsoventral $-4.8 \mathrm{~mm}$, angled $30^{\circ}$ laterally) (Paxinos and Watson, 2007). This approach allows minimal spread to prelimbic cortex (PL) dorsal to IL, a region responsible for expression of conditioned fear (Sierra-Mercado et al., 2011). Microinjections $(0.5 \mu \mathrm{l} / \mathrm{side})$ of the inhibitory Gi-coupled DREADD (AAV5CaMKII $\alpha$-hM4Di-HA-IRES-mCitrine), the excitatory Gq-coupled DREADD (AAV5-CaMKII $\alpha$-hM3Dq-HA-IRES-mCitrine), or the control construct (AAV5-CaMKII $\alpha$-GFP) at $2.4 \times 10^{12}$ particles $/ \mathrm{ml}$ (UNC vector core, Chapel Hill, NC) (Armbruster et al., 2007) were injected at a rate of $0.25 \mu \mathrm{l} / \mathrm{min}$. The injectors remained in place $5 \mathrm{~min}$ before removing. The CaMKII $\alpha$ promoter was used to target DREADD expression specifically in glutamatergic projection neurons in IL (Liu and Jones, 1996; Goshen et al., 2011).

Immunohistochemistry. To determine localization and specificity of DREADD expression, rats were perfused $24 \mathrm{~h}$ after behavioral testing and immunohistochemistry performed on free-floating $40 \mu \mathrm{m}$ sections. After peroxidase quenching, sections were incubated in rabbit anti-GFP antibody (1:15,000, Millipore, RRID:AB_2630379) followed by biotinylated anti-rabbit secondary antibody $(1: 15,000$, Sigma, RRID: AB_258613). Sections were then incubated with an avidin-peroxidase conjugate (Vectastain ABC, Vector Laboratories, RRID:AB_2336819) followed by fluorescein-tagged tyramide reagent (PerkinElmer). To determine the specificity of viral expression in $\mathrm{CaMKII}^{+}$cells, sections were also incubated in either mouse anti-CaMKII antibody $(1: 10,000$, Invitrogen, RRID:AB_325403) or anti-GAD67 antibody (1:5000, Millipore, RRID:AB_2278725) followed by HRP-conjugated anti-mouse secondary antibody (1:2000, Cell Signaling Technology, RRID:AB_330924), then cyanine 3-tagged tyramide reagent.

Chronic unpredictable stress (CUS). As previously described (Bondi et al., 2008; Fucich et al., 2016), a different acute stressor was applied each day for $14 \mathrm{~d}$ (Table 1). Unstressed controls were handled daily. The 
extinction procedure took place $3 \mathrm{~d}$ after the end of CUS. In experiments testing cognitive flexibility on the attentional set-shifting test (AST), this allowed for the $2 \mathrm{~d}$ of habituation and training before extinction. Behavioral testing on either the AST or the shock-probe defensive burying test (SPDB) was then conducted $24 \mathrm{~h}$ after extinction.

\section{Experiment 1. Necessity of $v m P F C$ activity for extinction training to reverse the CUS-induced deficit in coping behavior on the SPDB test}

A total of 94 rats were used in 8 groups, defined by Construct (hM4Di or GFP control), Stress (CUS or unstressed control), and Extinction (extinction or tone control). Rats received microinjections of virus into the vmPFC. After $10 \mathrm{~d}$ recovery, groups that were to undergo extinction were fear-conditioned while tone controls remained in their home cages. CUS began the day after conditioning (day 1). Three days after the end of CUS (day 17), all rats received an injection of the DREADD ligand clozapine$\mathrm{N}$-oxide (CNO, $1 \mathrm{mg} / \mathrm{kg}$ in $2.5 \% \mathrm{DMSO}$, i.p.) followed by the extinction procedure $30 \mathrm{~min}$ later. Tone control groups were also exposed to Context $\mathrm{B}$ and the presentation of tones, but as they had not been fearconditioned, this produced no extinction learning. Levels of CNO after this dose have been shown to peak in rats at $30 \mathrm{~min}$ and to decline to very low levels by $6 \mathrm{~h}$ after injection, and thus should not be active at the time of testing $24 \mathrm{~h}$ later (MacLaren et al., 2016). All rats were tested on the SPDB test on day 18 (see Fig. 2A).

Extinction treatment. Two days before beginning CUS, all rats (in both the extinction and tone control groups) were habituated to two contexts in sound-attenuating cabinets for $15 \mathrm{~min}$ each. Context A was the conditioning chamber $(30.5 \times 25.4 \times 30.5 \mathrm{~cm}$; model H10-11R-TC, Coulbourn Instruments) with square metal walls and a metal grid floor attached to a shock generator (model H13-15). Context B was a different chamber, with a smooth green vinyl floor and circular vinyl walls.

Day 0: fear conditioning. Rats that were to receive extinction treatment on day 17 underwent fear conditioning in Context A on day 0 . To avoid CUS altering fear conditioning, rats were fear-conditioned the day before beginning CUS, with 4 pairings of a tone $(10 \mathrm{kHz}, 75 \mathrm{~dB}, 20 \mathrm{~s})$ coterminus with footshock $(0.8 \mathrm{~mA}, 0.5 \mathrm{~s})$. Average intertrial interval was $120 \mathrm{~s}$. Conditioned fear was expressed as percentage freezing during each tone, measured videographically and defined as movement falling below the motion index threshold for at least $1 \mathrm{~s}$ (FreezeView software, ActiMetrics \#ACT-100, Coulbourn Instruments, RRID:SCR_014429). Subjects were then assigned to CUS or control groups such that initial freezing was comparable.

Day 17: extinction. Three days after the end of CUS, rats underwent a single extinction session in Context $\mathrm{B}$, consisting of 16 presentations of tone alone, with no shock (average intertrial interval $120 \mathrm{~s}$ ). This produces freezing behavior that is typically maximal on the second extinction trial $(\sim 70 \%)$, decreasing over $7-10$ trials to a final level of $\sim 25 \%$ (Green et al., 2011). All rats underwent the same extinction procedure on day 17. Rats in the tone control group did not receive prior fear conditioning, thus controlling for any potential effects of environmental enrichment alone by exposure to the tones in Context $\mathrm{B}$, independent of extinction learning.

Shock-probe defensive burying test. The rat was placed in a modified $42 \times 20 \times 20 \mathrm{~cm}$ Plexiglas cage filled with $5 \mathrm{~cm}$ of bedding material. The test cage had a $2-\mathrm{cm}$-diameter hole in one end $7 \mathrm{~cm}$ above the floor, into which a glass probe ( $1 \mathrm{~cm}$ diameter; $6 \mathrm{~cm}$ long) wrapped in copper wire was inserted to be positioned $2 \mathrm{~cm}$ above the surface of the bedding material. The probe was connected to a shock generator (Coulbourn Instruments H13-15) set to deliver $2 \mathrm{~mA}$ current upon contact by the rat. To begin the test, the rat was placed into the far end of the test chamber facing away from the probe. Rats typically made contact with the probe within $30 \mathrm{~s}$. After the rat contacted the probe and received a single shock, the current was turned off to prevent any subsequent shock. Behavior was then recorded for $15 \mathrm{~min}$ by a video camera and stored for offline analysis by an experimenter blind to the treatment groups. Behaviors scored included the amount of time the rat spent actively burying the probe and the total time spent immobile during the 15 min test period. Data were then analyzed and reported as the bury ratio, which is the time spent burying divided by the time spent burying plus time spent immobile, thus representing the proportion of active coping behavior.

Immunohistochemistry. To verify that the Gi-DREADD effectively blocked extinction-induced vmPFC activity, cFos expression was analyzed in a separate cohort of 9 rats in 3 groups (GFP/tone control, GFP/ extinction, or hM4Di/extinction). Rats were injected with CNO (1 mg/ kg, i.p.) 30 min before extinction. One hour after completing extinction, rats were perfused and immunohistochemistry was performed. After peroxidase quenching, $40 \mu \mathrm{m}$ sections through the mPFC were incubated in primary rabbit anti-cFos antibody (1:5000, Millipore, RRID: AB_2631318) followed by HRP-conjugated anti-rabbit secondary antibody (1:2000, Cell Signaling Technology, RRID:AB_2099233), then fluorescein-tagged tyramide reagent (PerkinElmer). Fos-positive cells were counted in a standard $200 \mu \mathrm{m}^{2}$ field defining the IL cortex in three sections per rat.

\section{Experiment 2. Sufficiency of $v m P F C$ activity to mimic the therapeutic effects of extinction training on coping behavior in the SPDB test}

A total of 33 rats were used in 4 groups, defined by Construct (hM3Dq or GFP) and Stress (CUS or control). Rats received microinjections of virus containing the CaMKII $\alpha$-driven Gq-DREADD hM3Dq or GFP control constructs into the vmPFC as above. After $11 \mathrm{~d}$ recovery, CUS or control treatment began (day 1). A single administration of CNO (1 mg/kg, i.p.) was given $3 \mathrm{~d}$ after the end of CUS (day 17). All rats were tested on the SPDB test $24 \mathrm{~h}$ after CNO injection (see Fig. $3 A$ ). To verify that hM3Dq induced vmPFC activity, cFos expression was analyzed in a separate cohort of 6 rats in 2 groups (GFP or hM3Dq). Four weeks after viral injection, rats were injected with $\mathrm{CNO}(1 \mathrm{mg} / \mathrm{kg}$, i.p. $)$ and perfused $90 \mathrm{~min}$ later. Immunohistochemistry was performed as above.

\section{Experiment 3. Necessity and sufficiency of vmPFC activity for the reversal of the CUS-induced deficit in cognitive flexibility in} the AST

A total of 42 rats were used in 7 groups: a control group (GFP/unstressed/ tone control); a stress group (GFP/CUS/tone control); an extinction therapy group (GFP/CUS/extinction); a group with vmPFC inhibited during extinction (hM4Di/CUS/extinction); a control group to demonstrate that inhibition of vmPFC alone did not compromise behavior on the AST $24 \mathrm{~h}$ later (hM4Di/unstressed/tone control); a group to test the sufficiency of activating vmPFC alone (hM3Dq/CUS/no extinction); and a site-specificity group (hM4Di given in PL followed by CUS/extinction). Rats received microinjections of virus into the vmPFC as above. The site-specificity group received bilateral injections targeting the PL cortex dorsal to IL (anteroposterior 2.9, mediolateral \pm 0.6 , dorsoventral -3.2 $\mathrm{mm}$ ). After $10 \mathrm{~d}$ recovery, groups that were to undergo extinction as well as the hM3Dq-injected rats were fear-conditioned. CUS or nonstress control treatment began the day after fear conditioning (day 1). Three days after the end of CUS (day 17), all rats received an injection of CNO ( $1 \mathrm{mg} / \mathrm{kg}$, i.p.). hM4Di- and GFP-expressing animals that had received fear conditioning then received the extinction procedure $30 \mathrm{~min}$ later. Tone controls were also exposed to Context $\mathrm{B}$ and the presentation of tones, but as they had not been fear-conditioned, this produced no extinction learning. hM3Dq-expressing animals remained in their home cages after $\mathrm{CNO}$ administration. All rats were tested on the AST $24 \mathrm{~h}$ later on day 18 (see Fig. 4A).

AST. Cognitive flexibility was measured in the extradimensional (ED) set-shifting task of the AST, as described previously (Lapiz and Morilak, 2006; Bondi et al., 2008; Jett and Morilak, 2013). Beginning on day 11 of CUS, rats were food restricted to $12 \mathrm{~g} / \mathrm{d}$ to ensure motivation to dig for the food reward. The test requires $3 \mathrm{~d}$ as follows:

Day 15: habituation. One day after the end of CUS, rats were taught to dig for food reward (1/2 Honey Nut Cheerio, General Mills), in terracotta pots filled with sawdust, first in their home cage, then in the testing arena.

Day 16: training. Rats learned to make simple discriminations to locate the food reward, first by associating the reward with one of two odors (lemon- vs rosewood-scented pots, both filled with sawdust), then with one of two digging media (unscented pots filled with felt strips vs paper). 
Day 18: testing (24 h after CNO). As described previously (Bondi et al., 2008), testing consists of a series of discriminations in which the rats learn to locate the food reward based on association with a cue in one of the two stimulus dimensions. Once they master a given contingency, indicated by reaching the criterion of 6 consecutive correct trials, the rules are changed and the rat must adapt to learn the new rule. In the first 5 stages, including a simple discrimination, complex discrimination, reversal learning, new acquisition, and second reversal, the rats form a "cognitive set," learning that the same stimulus dimension (i.e., either odor or texture) is informative however the rules are changed. However, in the sixth stage, the ED set-shift, the previously irrelevant dimension becomes relevant and the previously relevant dimension becomes the distractor, requiring the rat to abandon its cognitive set and shift attention from one stimulus dimension to the other (e.g., from odor to medium). This ED cognitive set shift is dependent on the mPFC (Birrell and Brown, 2000). Testing on each task continued to a criterion of six consecutive correct trials before proceeding to the next task. The measure of cognitive flexibility was the number of trials to criterion (TTC) on the ED task. Behavior was scored by experimenters blind to treatment groups.

Experiment 4. Effects of CUS and extinction on afferent-evoked field potentials recorded in the $M P F C$ in response to stimulation in the mediodorsal thalamus (MDT)

A total of 24 rats were used in 4 groups, defined by Stress (CUS or control) and Extinction (extinction or tone control). Groups were treated as above. Three days after the end of CUS (day 17), rats underwent extinction or tone control treatment. The following day (Day 18), corresponding to the behavioral test day in the experiments above, afferent-evoked field potentials were recorded in the mPFC. Rats were anesthetized (chloral hydrate, $400 \mathrm{mg} / \mathrm{kg}$, i.p.) and placed in a stereotaxic apparatus. A bipolar concentric stimulating electrode with an inner electrode extending $1 \mathrm{~mm}$ (Plastics One) was lowered into the left MDT (from bregma: anteroposterior -2.5 , mediolateral \pm 0.9 , dorsoventral $-5.0 \mathrm{~mm}$ ), and a tungsten recording electrode was lowered into the left mPFC (anteroposterior 3.0, mediolateral \pm 0.6 , dorsoventral: -3.5 to $4.0 \mathrm{~mm}$ ). Body temperature was maintained at $37^{\circ} \mathrm{C}$. Local field potentials were evoked in the MPFC by stimulating the MDT ( 30 pulses, $260 \mu$ s pulse width, $0.1 \mathrm{~Hz}$ ) in $100 \mu \mathrm{A}$ increments from 100 to 600 $\mu \mathrm{A}$ for $5 \mathrm{~min}$ to construct current-response curves. Recorded potentials were amplified (gain $5000 \times$, low cutoff $0.3 \mathrm{~Hz}$, high cutoff $1000 \mathrm{~Hz}$ ) and digitized (Power Lab, $\mathrm{AD}$ Instruments) at a $2 \mathrm{kHz}$ sampling rate for offline analysis. The response was measured as the amplitude between the peak of the first negative deflection (N1), occurring $\sim 5-8 \mathrm{~ms}$ after stimulation, and the peak of the subsequent positive deflection (P2), at 15-18 ms (Herry et al., 1999).

Statistical analyses. Data were analyzed by one-, two-, or three-way ANOVA, with the exception of the cFos data in Experiment 2, which were analyzed by $t$ test. Pairwise comparisons to detect specific group differences were performed using Newman-Keuls test. For analysis of evoked potentials, after nonlinear regression, stimulus-response curves were compared by Least-Sums-of-Squares $F$ Test. Pairwise comparisons, determined a priori, between the CUS-tone control and unstressed-tone control groups, and between the CUS-tone control and CUS-extinction groups were conducted post hoc, applying the Bonferroni correction for multiple comparisons. Significance in all analyses was determined at $p<0.05$.

\section{Results}

\section{Experiment 1. Necessity of vmPFC activity for extinction to reverse the CUS-induced deficit in coping behavior on the SPDB test}

A representative image of the IL injection site and spread, as indicated by GFP immunoreactivity, is illustrated in Figure $1 \mathrm{~A}$. Expression was centered in and largely confined to the IL, with sparse expression in the ventral-most region of PL and along the forceps minor. Colocalization with CaMKII $\alpha$ was confirmed by immunohistochemistry, indicating expression of the viral con- struct in pyramidal cells, and no colocalization was seen with GAD67, indicating no transfection of interneurons (Fig. 1B,C).

One-way ANOVA revealed that extinction significantly induced cFos expression in IL $\left(F_{(2,6)}=80.9, p<0.0001\right)$. Newman-Keuls test revealed that, in the presence of CNO, cFos expression was elevated in IL after extinction in GFP-expressing animals compared with GFP-expressing tone controls $(p<$ $0.0001)$. Extinction-induced cFos expression was reduced in rats expressing hM4Di compared with GFP ( $p<0.0001$; Fig. $2 B)$, confirming the efficacy of $\mathrm{CNO}$ in inhibiting extinction-induced IL activity in the Gi-DREADD-expressing rats.

In the groups tested behaviorally, fear conditioning was comparable before CUS or control treatment, and extinction learning was not impacted by neuronal inhibition with hM4Di (area under the curve: $\left.F_{(1,46)}=0.03, p=0.8585\right)$, in agreement with previous observations (Do-Monte et al., 2015). Tone controls showed consistently low freezing during tone presentations on day 17 (36.6 $\pm 1.8 \%)$. Three-way ANOVA for effects on coping strategy in the SPDB test revealed a significant main effect of Stress $\left(F_{(1,86)}=19.6, p<0.0001\right)$, a significant Stress $\times$ Extinction interaction $\left(F_{(1,86)}=6.4, p=0.0133\right)$, and a significant Construct $\times$ Stress $\times$ Extinction interaction $\left(F_{(1,86)}=4.4, p=\right.$ 0.0378). Newman-Keuls comparisons revealed that CUS compromised active coping, decreasing the bury ratio in both GFP- and hM4Di-expressing tone control rats compared with GFP-expressing unstressed tone controls $(p=0.0035$ and $p=$ 0.0083 , respectively). Extinction training $24 \mathrm{~h}$ before testing reversed the stress effect, significantly increasing the bury ratio in GFP-expressing CUS rats $(p=0.0220)$, replicating previous findings (Fucich et al., 2016). The increase in bury ratio in CUS rats was prevented by $\mathrm{CNO}$ administration before extinction training in rats expressing hM4Di $(p=0.0182)$ (Fig. $2 C)$.

\section{Experiment 2. Sufficiency of vmPFC activity to mimic the therapeutic effects of extinction training on coping behavior} cFos was induced in IL of rats expressing hM3Dq 90 min after CNO administration $\left(t_{(4)}=34.8, p<0.0001\right.$; Fig. $\left.3 B\right)$, confirming the efficacy of hM3Dq to induce activity. Analysis of the bury ratio in the SPDB test revealed a significant Construct $\times$ Stress interaction $\left(F_{(1,29)}=6.8, p=0.0145\right)$, but no main effects. Newman-Keuls test revealed that CUS decreased the bury ratio of GFP control rats $(p=0.0437)$, reflecting a shift from active coping (burying) to passive coping (immobility). hM3Dq-mediated activation of IL restored the bury ratio in CUS rats back to control levels, tested 24 h later ( $p=0.0188$ compared with GFP/CUS animals) (Fig. 3C).

\section{Experiment 3. Necessity and sufficiency of vmPFC activity for the reversal of the CUS-induced deficit in cognitive flexibility in the AST}

Fear conditioning was comparable in all groups before CUS or control treatment, and extinction was comparable in the groups that were fear conditioned (area under the curve: $F_{(2,18)}=1.6$, $p=0.2284)$. Tone controls showed consistently low freezing during tone presentations on day $17(34.7 \pm 8.4 \%)$.

One-way ANOVA revealed a significant effect on cognitive flexibility $\left(F_{(5,31)}=4.3, p=0.0027\right)$. Newman-Keuls test revealed that CUS compromised cognitive flexibility, increasing TTC on the ED task $(p=0.0281)$. Extinction training $24 \mathrm{~h}$ before testing had the expected therapeutic effect, reducing TTC in CUS rats compared with CUS/tone controls $(p=0.0222)$, restoring ED performance to unstressed control levels, replicating our previous findings (Fucich et al., 2016). The reduction in TTC in CUS 
A

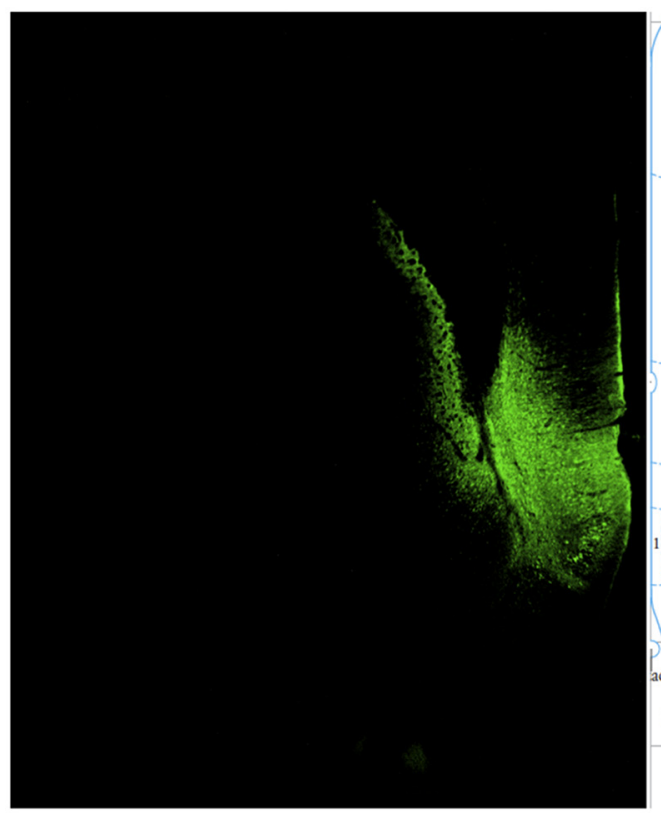

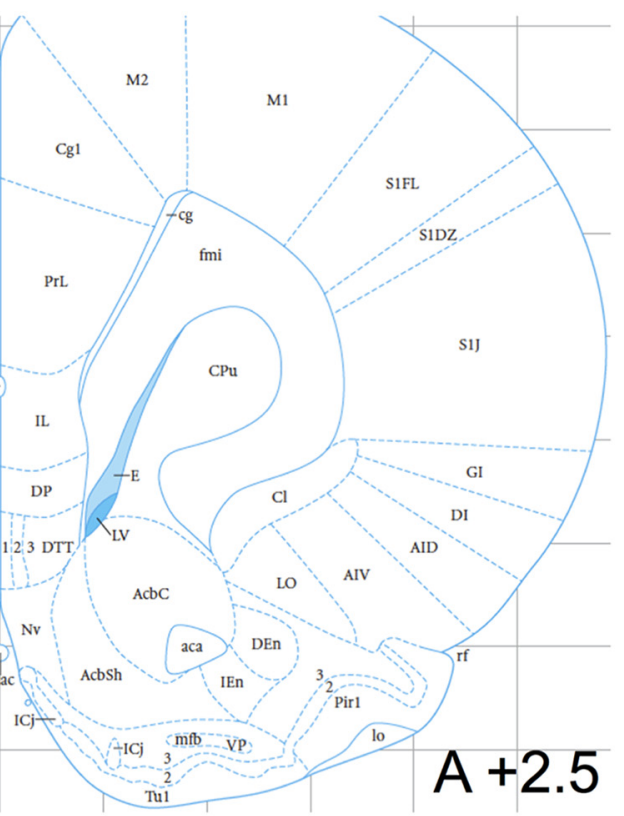

B

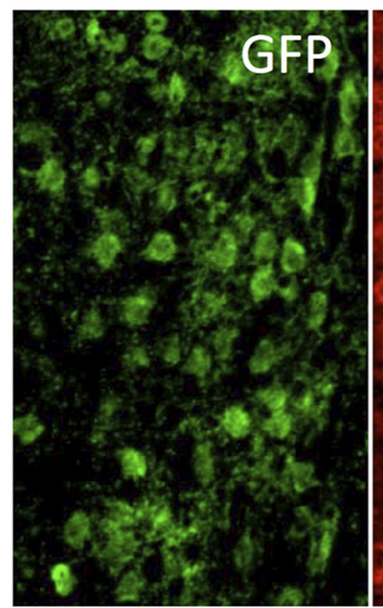

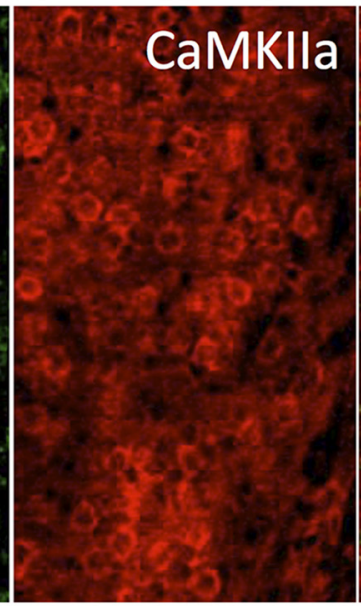

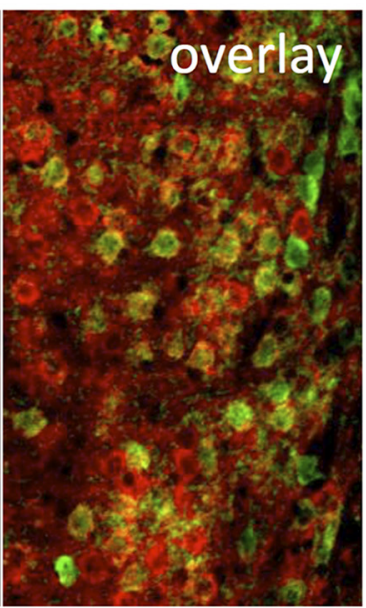

c
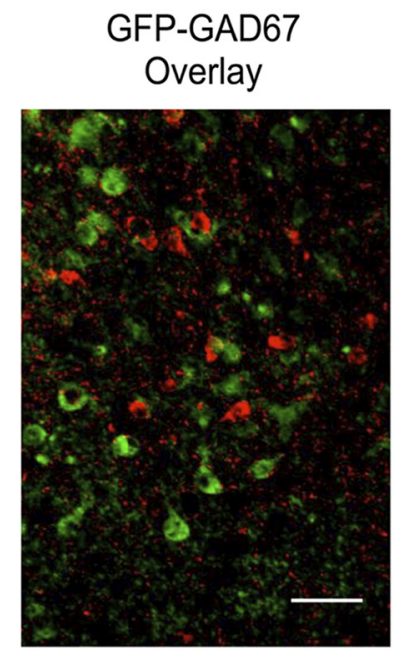

Figure 1. Virally delivered GFP expression is localized to CaMKII $\alpha^{+}$cells in IL cortex. A, GFP immunofluorescence shows that expression is centered in, and largely confined to, the IL cortex of ventral $\mathrm{mPFC}$. There was sparse expression in the ventral-most region of PL cortex and along the margin of the forceps minor. Schematic diagram reproduced with permission from Paxinos and Watson (2007). B, GFP immunofluorescence is expressed in glutamatergic neurons in IL cortex (red CaMKIl $\alpha$ immunofluorescence). C, By contrast, there was no GFP expression seen in GABAergic interneurons (red GAD67 immunofluorescence). Scale bar, $25 \mu \mathrm{m}$.

rats was prevented by $\mathrm{CNO}$ administration before extinction training in rats expressing hM4Di $(p=0.0369)$. Similar to the effect of extinction training, activation of the IL alone by CNO administration $24 \mathrm{~h}$ before testing to rats expressing hM3Dq in IL reduced TTC in CUS rats compared with CUS/tone controls $(p=0.0376)$, restoring ED performance to unstressed control levels. CNO given on day 17 to nonstressed rats expressing hM4Di in IL did not in itself impair set-shifting performance on day 18, suggesting that the effect of inhibiting vmPFC during extinction was a blockade of the therapeutic effect, rather than a nonspecific deficit that opposed or masked the effect of extinction. Finally, CNO administration before extinction in rats expressing hM4Di in PL cortex also prevented the reduction in TTC in CUS rats $(p=0.0477$; Fig. $4 B)$. A representative image of the PL injection site and spread, as indicated by GFP immunoreactivity, is illustrated in Figure $4 C$.
Experiment 4. Effects of CUS and extinction on afferentevoked field potentials recorded in the $\mathrm{MPFC}$ in response to stimulation in the MDT

Stimulus-response curves for MDT afferent-evoked field potentials recorded in the mPFC differed significantly after stress and extinction treatment $\left(F_{(9,132)}=2.182, p=0.0270\right.$; Fig. 5). CUS significantly attenuated the response (CUS-tone control compared with unstressed-tone control: $\left.F_{(3,78)}=4.094, p=0.0090\right)$. Extinction treatment after CUS restored evoked responses to control levels (CUS-tone control compared with CUS-extinction: $\left.F_{(3,72)}=7.466, p=0.0002\right)$.

\section{Discussion}

The results of this study demonstrate the necessity of activating the vmPFC for the therapeutic effects of cue-conditioned fear extinction as a behavioral intervention after chronic stress in rats. 


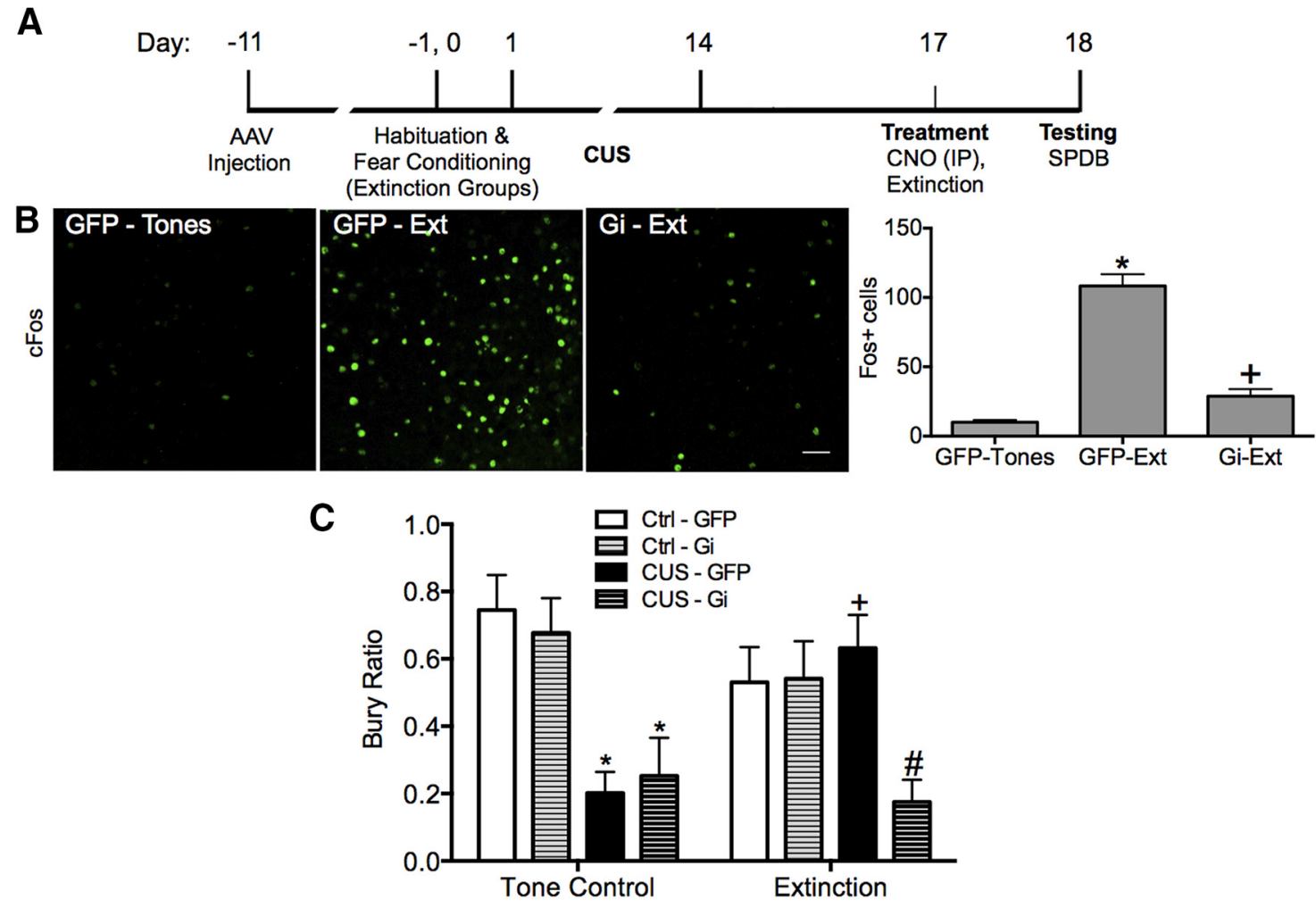

Figure 2. Extinction requires IL activity to rescue stress-compromised coping. $A$, Timeline for Experiment $1 . B$, In a separate cohort of rats, CNO (1 mg/kg, i.p.) was administered 30 min before extinction, and the induction of cFos protein expression was measured in IL cortex $1 \mathrm{~h}$ after completion of extinction training in GFP- or hM4Di-expressing animals. Extinction induced cFos in IL compared with tone controls. ${ }^{*} p<0.0001$. Activation of the hM4Di DREADD with CN0 inhibited that induction. ${ }^{+} p<0.0001 . n=3$ per group. Scale bar, $50 \mu \mathrm{m}$. C, CUS induced a significant decrease in the bury ratio, calculated as bury time/(bury time + immobility time). ${ }^{*} p<0.01$, both GFP/CUS/tone controls and hM4Di/CUS/tone controls compared with GFP/unstressed/tone controls. Extinction treatment reversed the effect of stress, restoring the bury ratio to unstressed control levels. ${ }^{+} p<0.05$, GFP/CUS/extinction compared with GFP/CUS/tone controls. Inhibition of IL activity during extinction treatment prevented the therapeutic rescue of CUS-compromised bury ratio. ${ }^{\#} p<0.02$, hM4Di/CUS/extinction compared with GFP/CUS/extinction. $n=9-14$ per group. In all panels, data are mean \pm SEM.

Extinction treatment ameliorated the CUS-induced shift from active to passive coping behavior on the SPDB test as well as the CUS-induced deficit in mPFC-mediated cognitive flexibility on the AST, tested $24 \mathrm{~h}$ after extinction. Inhibition of IL projection neurons during extinction prevented these therapeutic effects. Moreover, the beneficial effect of extinction was mimicked by transiently increasing the activity of IL projection neurons, suggesting that plasticity resulting from increased activity in this cell population accounted for the long-lasting effects seen $24 \mathrm{~h}$ later, when $\mathrm{CNO}$ was no longer present. Further, as we reported previously (Jett et al., 2017), CUS attenuated the vmPFC response to excitatory afferent stimulation, and extinction reversed this reduction in afferent-evoked response, supporting the suggestion that the therapeutic mechanism underlying extinction therapy involves activity-dependent plasticity in the vmPFC, which restores responsivity and function of this brain region after stress.

The findings in the present study support the idea that engaging the vmPFC (e.g., with extinction learning) during behavioral therapy for stress-related psychiatric disorders, and the consequent plasticity induced in this brain region, may be critical to improve the function of a hyporesponsive vmPFC (Elzinga and Bremner, 2002) to resolve prefrontal-related symptom dimensions, such as maladaptive coping behavior and cognitive inflexibility, which have been implicated in both the onset and maintenance of disease (Beck, 1976; Foa and Kozak, 1986; Wenzlaff et al., 1988; Creamer et al., 1992; Mathews and Mackintosh, 1998; Coles and Heimberg, 2002). Our findings that increasing
vmPFC pyramidal cell activity rescues these stress-compromised behaviors suggest that stimulation of this region, perhaps engaging similar circuits as those activated by fear extinction via vmPFC projections to subcortical targets, is sufficient to produce the plastic changes necessary to improve stress-compromised vmPFC function. Other preclinical studies have shown that electrical stimulation of the vmPFC in rats has antidepressant-like effects in the forced swim test (Hamani et al., 2010a, b; Warden et al., 2012). Our results demonstrate a beneficial effect of increasing the activity of IL projection cells specifically, in agreement with those of a recent study demonstrating that optogenetic stimulation of IL in rats improves measures of anhedonia and anxiety and reduces immobility on the forced swim test $24 \mathrm{~h}$ after stimulation (Fuchikami et al., 2015). Such preclinical evidence would suggest that vmPFC stimulation could function as a stand-alone treatment for stress-related psychopathologies. Indeed, improvements have been seen in patients with depression after deep brain stimulation of the subcallosal cingulate gyrus (SCG) (Mayberg et al., 2005; Lozano et al., 2008). It is important to note, however, that Mayberg et al. (2005) suggest that the pattern of stimulation they used actually reduces hyperactivity they have observed in the SCG. This is in distinct contrast to a substantive literature demonstrating hypoactivity of medial prefrontal regions in depression and related disorders (for review, see Salerian and Altar, 2012). They have suggested that different subtypes of depression may be associated with hyperactivity and hypoactivity of the vmPFC, the former responding to deep brain stimulation of the 
SCG, whereas the latter may respond to cognitive behavioral therapy (McGrath et al., 2013; Dunlop et al., 2017). Because IL stimulation enhances fear extinction in rodents (Milad et al., 2004; Vidal-Gonzalez et al., 2006; Maroun et al., 2012), these observations suggest that augmenting vmPFC activity could specifically enhance the efficacy of behavioral therapy.

Our results showing that chronic stress decreases afferent-evoked field potentials in the mPFC agrees with reports that chronic stress leads to atrophy of mPFC projection neurons (Cerqueira et al., 2005; Liston et al., 2006), decreases expression of glutamate receptors in the mPFC (Gourley et al., 2009; Yuen et al., 2012; D.P. et al., unpublished data), and causes elaboration of mPFC inhibitory neurons (Gilabert-Juan et al., 2013), which overall are likely to suppress $\mathrm{mPFC}$ activity and responsiveness. These data correspond to clinical evidence showing decreased PFC volume and dysfunctional mPFC activity in patients with stressrelated psychiatric disease (Drevets et al., 1997; Gur et al., 2000; Mayberg et al., 2005; Drevets et al., 2008). In the present study, extinction treatment rescued stress-compromised $\mathrm{mPFC}$ responsivity in addition to stress-compromised $\mathrm{mPFC}$ related behaviors $24 \mathrm{~h}$ later. Similarly, activating mPFC projection neurons via DREADDs also improved stresscompromised behaviors $24 \mathrm{~h}$ later, when

$\mathrm{CNO}$ is no longer present. Together, these results show that extinction learning produces activity-dependent plastic changes in $\mathrm{mPFC}$ function sufficient to reverse the effects of stress for at least $24 \mathrm{~h}$ after behavioral intervention. Further studies are needed to explore the duration of these beneficial effects.

It is likely that activity-dependent processes in vmPFC not only restore its function, allowing improved performance when challenged by a threatening situation or a change in environmental contingencies, but also that activating the projection cells in vmPFC can affect plasticity in downstream targets, such as the amygdala. Indeed, the amygdala is known to be hyperexcitable in patients with stress-related psychiatric illness, and psychotherapy has been shown to reduce reactivity of the amygdala (Drevets, 2000; Ritchey et al., 2011). Furthermore, the role of the ILamygdala circuit in fear extinction is well established. It is also known that the IL sends direct projections to the lateral septum (Vertes, 2004). Because active coping in the SPDB test is mediated by the lateral septum (Treit et al., 1993; Koolhaas et al., 1999; Bondi et al., 2007), and modulated by the mPFC (Shah et al., 2004), it is possible that activity in the IL projection cells alters plasticity in this brain region as well, to improve the selection of an adaptive coping style when presented with a threat $24 \mathrm{~h}$ later. Indeed, we found previously that phosphorylation of ribosomal protein S6, used as a marker of activity-dependent protein synthesis (Knight et al., 2012), was increased in the lateral septum following extinction treatment (Fucich et al., 2016).
We also showed previously that protein synthesis in the PL cortex, dorsal to the IL, was not required for the therapeutic effect of extinction on set-shifting (Fucich et al., 2016). However, perhaps surprisingly, inhibiting PL during extinction in the present study attenuated the therapeutic effect. If Gi-DREADD expression had spread to the IL, inhibition of IL could account for this result. However, expression appeared confined to the target region in PL; thus, the possibility that IL inhibition alone accounted for the attenuation of therapeutic effect in this group is unlikely. Alternatively, PL pyramidal cell activity during extinction could potentially contribute to the resulting plasticity in IL cortex that underlies the beneficial effects of extinction on set-shifting. Although direct PL-to-IL projections are relatively sparse, reducing the likelihood that PL activity might influence IL activity (Fisk and Wyss, 1999), projections from IL to PL are even more sparse (Gabbott et al., 2003), yet optogenetic stimulation of IL pyramidal cells altered pyramidal cell activity in the PL (Ji and Neugebauer, 2012). Thus, it remains possible that PL activity could similarly influence IL activity. PL activity during fear extinction could also influence IL activity indirectly, perhaps via PL projections to the amygdala. Inhibiting the PL during extinction does not impair extinction retrieval later, suggesting that PL activity is not necessary for consolidation of extinction, in contrast to the necessity of IL activity (Sierra-Mercado et al., 2011). However, reciprocal connections between the PL and BLA are known to be active during extinction training, and BLA projections can impact the firing of IL cells during extinction (Senn et al., 2014). 
A
Day:
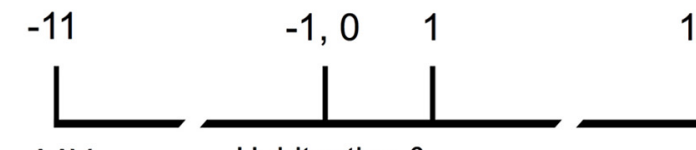
1415,16
17
Treatment

B

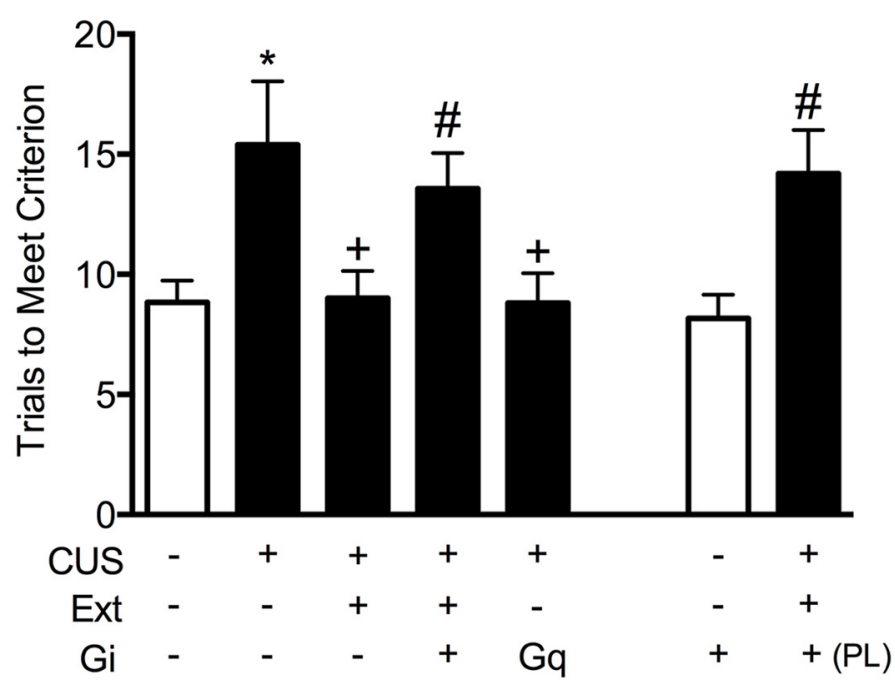

C
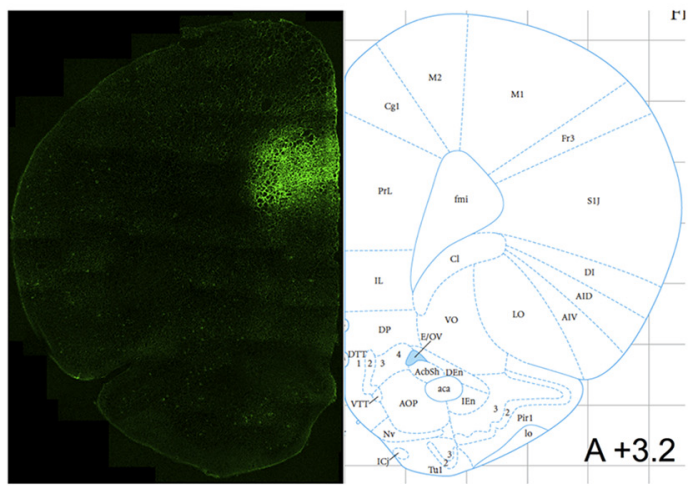

Figure 4. IL activity is necessary and sufficient to rescue stress-compromised cognitive flexibility. $\boldsymbol{A}$, Timeline for Experiment 3. $\boldsymbol{B}$, CUS compromised cognitive flexibility, significantly increasing TTC on the ED set-shifting task. ${ }^{*} p<0.05, \mathrm{GFP} / \mathrm{CUS} /$ tone controls compared with GFP/unstressed/tone controls. Both extinction treatment and hM3Dq activation with CNO reversed the effect of stress, restoring TTC to unstressed control levels. ${ }^{+} p<0.05$, GFP/CUS/extinction and hM3Dq/CUS compared with GFP/CUS/tone controls. hM4Di-mediated inhibition of IL projection neurons during extinction treatment prevented the beneficial effect on set-shifting after CUS, as TTC were comparable with GFP/CUS/tone controls. ${ }^{\#} p<0.05$, hM4Di/CUS/extinction compared with GFP/CUS/ extinction. Likewise, inhibiting glutamatergic neurons in PL cortex during extinction also prevented the beneficial effect on set-shifting. ${ }^{\#}<0.05$, hM4Di in PL/CUS/extinction compared with GFP/CUS/extinction. hM4Di-mediated inhibition of IL projection neurons of unstressed tone controls had no effect on set-shifting tested $24 \mathrm{~h}$ later; $n=5-9$ per group. Data are mean \pm SEM. $C$, GFP immunofluorescence shows that expression targeting PL is confined to the PL. Schematic diagram reproduced with permission from Paxinos and Watson (2007).

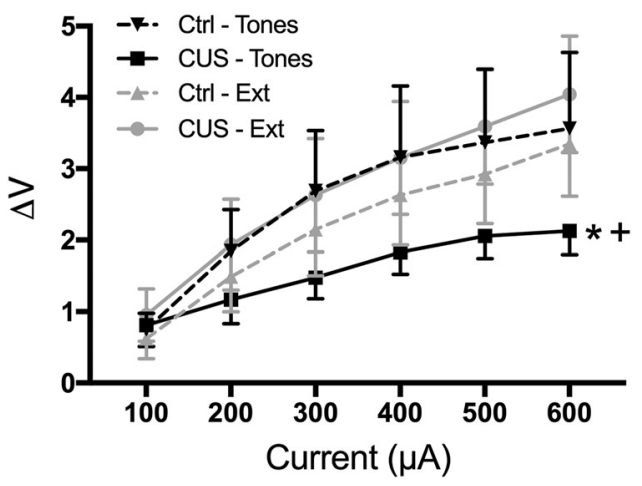

Figure 5. Extinction rescues stress-induced attenuation of medial prefrontal cortical responsivity. Timeline for Experiment 4. CUS compromised afferent-evoked field potentials recorded in the $\mathrm{mPFC}$ in response to stimulation of the medial dorsal thalamus. ${ }^{*} p<0.01$, CUS/tone controls compared with unstressed/tone controls. Extinction treatment reversed the effect of stress, restoring evoked responses to unstressed control levels. ${ }^{+} p<0.001$, CUS/extinction compared with CUS/tone controls. $n=5-8$ rats per group. Data are mean \pm SEM.

BLA inactivation with the $\mathrm{GABA}_{\mathrm{A}}$ agonist muscimol during extinction training has been shown to impair extinction consolidation (Sierra-Mercado et al., 2011). Thus, it is possible that extinction-induced activity in this circuit contributes to the plastic changes that underlie the beneficial effects on set-shifting in the mPFC $24 \mathrm{~h}$ later. This requires further investigation.

In conclusion, this study demonstrates the critical role of vmPFC activity in the therapeutic effects of fear extinction as a behavioral intervention in rats, improving stress-compromised coping behavior and cognitive flexibility deficits. This study also showed that chronic stress decreased the response of vmPFC to afferent stimulation, and extinction reversed this stress-induced decrease in $\mathrm{mPFC}$ responsivity, providing potential insight into mechanisms underlying stress-related cognitive pathology and mechanisms by which behavioral therapies may effectively treat such pathology. Together, these data support the idea that modulating the activity of the vmPFC may be a useful adjunctive treatment to improve cognitive behavioral therapies for posttraumatic stress disorder and other stress-related psychiatric illnesses.

\section{References}

Armbruster BN, Li X, Pausch MH, Herlitze S, Roth BL (2007) Evolving the lock to fit the key to create a family of $\mathrm{G}$ protein-coupled receptors potently activated by an inert ligand. Proc Natl Acad Sci U S A 104:51635168. CrossRef Medline

Beck AT (1976) Cognitive therapy and the emotional disorders. New York, NY: International University.

Birrell JM, Brown VJ (2000) Medial frontal cortex mediates perceptual attentional set shifting in the rat. J Neurosci 20:4320-4324. Medline

Bondi CO, Barrera G, Lapiz MD, Bedard T, Mahan A, Morilak DA (2007) Noradrenergic facilitation of shock-probe defensive burying in lateral septum of rats, and modulation by chronic treatment with desipramine. Prog Neuropsychopharmacol Biol Psychiatry 31:482-495. CrossRef Medline

Bondi CO, Rodriguez G, Gould GG, Frazer A, Morilak DA (2008) Chronic unpredictable stress induces a cognitive deficit and anxiety-like behavior 
in rats that is prevented by chronic antidepressant drug treatment. Neuropsychopharmacology 33:320-331. CrossRef Medline

Cerqueira JJ, Pêgo JM, Taipa R, Bessa JM, Almeida OF, Sousa N (2005) Morphological correlates of corticosteroid-induced changes in prefrontal cortex-dependent behaviors. J Neurosci 25:7792-7800. CrossRef Medline

Coles ME, Heimberg RG (2002) Memory biases in the anxiety disorders: current status. Clin Psychol Rev 22:587-627. CrossRef Medline

Creamer M, Burgess P, Pattison P (1992) Reaction to trauma: a cognitive processing model. J Abnorm Psychol 101:452-459. CrossRef Medline

de Kleine RA, Rothbaum BO, van Minnen A (2013) Pharmacological enhancement of exposure-based treatment in PTSD: a qualitative review. Eur J Psychotraumatol 4:21626. CrossRef Medline

Do-Monte FH, Manzano-Nieves G, Quiñones-Laracuente K, Ramos-Medina L, Quirk GJ (2015) Revisiting the role of infralimbic cortex in fear extinction with optogenetics. J Neurosci 35:3607-3615. CrossRef Medline

Drevets WC (2000) Functional anatomical abnormalities in limbic and prefrontal cortical structures in major depression. Prog Brain Res 126:413431. CrossRef Medline

Drevets WC, Price JL, Simpson JR Jr, Todd RD, Reich T, Vannier M, Raichle ME (1997) Subgenual prefrontal cortex abnormalities in mood disorders. Nature 386:824-827. CrossRef Medline

Drevets WC, Price JL, Furey ML (2008) Brain structural and functional abnormalities in mood disorders: implications for neurocircuitry models of depression. Brain Struct Funct 213:93-118. CrossRef Medline

Dunlop BW, Rajendra JK, Craighead WE, Kelley ME, McGrath CL, Choi KS, Kinkead B, Nemeroff CB, Mayberg HS (2017) Functional connectivity of the subcallosal cingulate cortex and differential outcomes to treatment with cognitive-behavioral therapy or antidepressant medication for major depressive disorder. Am J Psychiatry 174:533-545. CrossRef Medline

Elzinga BM, Bremner JD (2002) Are the neural substrates of memory the final common pathway in posttraumatic stress disorder (PTSD)? J Affect Disord 70:1-17. CrossRef Medline

Fisk GD, Wyss JM (1999) Associational projections of the anterior midline cortex in the rat: intracingulate and retrosplenial connections. Brain Res 825:1-13. CrossRef Medline

Foa EB, Kozak MJ (1986) Emotional processing of fear: exposure to corrective information. Psychol Bull 99:20-35. CrossRef Medline

Foa EB, Meadows EA (1997) Psychosocial treatments for posttraumatic stress disorder: a critical review. Annu Rev Psychol 48:449-480. CrossRef Medline

Fuchikami M, Thomas A, Liu R, Wohleb ES, Land BB, DiLeone RJ, Aghajanian GK, Duman RS (2015) Optogenetic stimulation of infralimbic PFC reproduces ketamine's rapid and sustained antidepressant actions. Proc Natl Acad Sci U S A 112:8106-8111. CrossRef Medline

Fucich EA, Paredes D, Morilak DA (2016) Therapeutic effects of extinction learning as a model of exposure therapy in rats. Neuropsychopharmacology 41:3092-3102. CrossRef Medline

Fucich E, Saunders M, Morilak DA (2015) Modeling cognitive therapy in rats: fear extinction reverses the chronic stress-induced shift from active to passive coping behavior. Neuropsychopharmacology 40 [Suppl. 1]: S120-S121.

Gabbott PL, Warner TA, Jays PR, Bacon SJ (2003) Areal and synaptic interconnectivity of prelimbic (area 32), infralimbic (area 25) and insular cortices in the rat. Brain Res 993:59-71. CrossRef Medline

Gilabert-Juan J, Castillo-Gomez E, Guirado R, Moltó MD, Nacher J (2013) Chronic stress alters inhibitory networks in the medial prefrontal cortex of adult mice. Brain Struct Funct 218:1591-1605. CrossRef Medline

Goshen I, Brodsky M, Prakash R, Wallace J, Gradinaru V, Ramakrishnan C, Deisseroth K (2011) Dynamics of retrieval strategies for remote memories. Cell 147:678-689. CrossRef Medline

Gourley SL, Kedves AT, Olausson P, Taylor JR (2009) A history of corticosterone exposure regulates fear extinction and cortical NR2B, GluR2/3, and BDNF. Neuropsychopharmacology 34:707-716. CrossRef Medline

Green MK, Rani CS, Joshi A, Soto-Piña AE, Martinez PA, Frazer A, Strong R, Morilak DA (2011) Prenatal stress induces long term stress vulnerability, compromising stress response systems in the brain and impairing extinction of conditioned fear after adult stress. Neuroscience 192:438451. CrossRef Medline

Gur RE, Cowell PE, Latshaw A, Turetsky BI, Grossman RI, Arnold SE, Bilker WB, Gur RC (2000) Reduced dorsal and orbital prefrontal gray matter volumes in schizophrenia. Arch Gen Psychiatry 57:761-768. CrossRef Medline
Hamani C, Diwan M, Isabella S, Lozano AM, Nobrega JN (2010a) Effects of different stimulation parameters on the antidepressant-like response of medial prefrontal cortex deep brain stimulation in rats. J Psychiatr Res 44:683-687. CrossRef Medline

Hamani C, Diwan M, Macedo CE, Brandão ML, Shumake J, Gonzalez-Lima F, Raymond R, Lozano AM, Fletcher PJ, Nobrega JN (2010b) Antidepressant-like effects of medial prefrontal cortex deep brain stimulation in rats. Biol Psychiatry 67:117-124. CrossRef Medline

Herry C, Vouimba RM, Garcia R (1999) Plasticity in the mediodorsal thalamo-prefrontal cortical transmission in behaving mice. J Neurophysiol 82:2827-2832. CrossRef Medline

Hofmann SG (2008) Cognitive processes during fear acquisition and extinction in animals and humans: implications for exposure therapy of anxiety disorders. Clin Psychol Rev 28:199-210. CrossRef Medline

Jett JD, Morilak DA (2013) Too much of a good thing: blocking noradrenergic facilitation in medial prefrontal cortex prevents the detrimental effects of chronic stress on cognition. Neuropsychopharmacology 38: 585-595. CrossRef Medline

Jett JD, Bulin SE, Hatherall LC, McCartney CM, Morilak DA (2017) Deficits in cognitive flexibility induced by chronic unpredictable stress are associated with impaired glutamate neurotransmission in the rat medial prefrontal cortex. Neuroscience 346:284-297. CrossRef Medline

Ji G, Neugebauer V (2012) Modulation of medial prefrontal cortical activity using in vivo recordings and optogenetics. Mol Brain 5:36. CrossRef Medline

Knight ZA, Tan K, Birsoy K, Schmidt S, Garrison JL, Wysocki RW, Emiliano A, Ekstrand MI, Friedman JM (2012) Molecular profiling of activated neurons by phosphorylated ribosome capture. Cell 151:1126-1137. CrossRef Medline

Koolhaas JM, Korte SM, De Boer SF, Van Der Vegt BJ, Van Reenen CG, Hopster H, De Jong IC, Ruis MA, Blokhuis HJ (1999) Coping styles in animals: current status in behavior and stress-physiology. Neurosci Biobehav Rev 23:925-935. CrossRef Medline

Lapiz MD, Morilak DA (2006) Noradrenergic modulation of cognitive function in rat medial prefrontal cortex as measured by attentional set shifting capability. Neuroscience 137:1039-1049. CrossRef Medline

Liston C, Miller MM, Goldwater DS, Radley JJ, Rocher AB, Hof PR, Morrison JH, McEwen BS (2006) Stress-induced alterations in prefrontal cortical dendritic morphology predict selective impairments in perceptual attentional set-shifting. J Neurosci 26:7870-7874. CrossRef Medline

Liu XB, Jones EG (1996) Localization of alpha type II calcium calmodulindependent protein kinase at glutamatergic but not gamma-aminobutyric acid (GABAergic) synapses in thalamus and cerebral cortex. Proc Natl Acad Sci U S A 93:7332-7336. CrossRef Medline

Lozano AM, Mayberg HS, Giacobbe P, Hamani C, Craddock RC, Kennedy SH (2008) Subcallosal cingulate gyrus deep brain stimulation for treatment-resistant depression. Biol Psychiatry 64:461-467. CrossRef Medline

MacLaren DA, Browne RW, Shaw JK, Radhakrishnan SK, Khare P, España RA, Clark SD (2016) Clozapine N-oxide administration produces behavioral effects in Long-Evans rats: implications for designing DREADD experiments. eNeuro 3:e0219. CrossRef Medline

Maroun M, Kavushansky A, Holmes A, Wellman C, Motanis H (2012) Enhanced extinction of aversive memories by high-frequency stimulation of the rat infralimbic cortex. PLoS One 7:e35853. CrossRef Medline

Mathews A, Mackintosh B (1998) A cognitive model of selective processing in anxiety. Cogn Ther Res 22:539-560. CrossRef

Mayberg HS, Lozano AM, Voon V, McNeely HE, Seminowicz D, Hamani C, Schwalb JM, Kennedy SH (2005) Deep brain stimulation for treatmentresistant depression. Neuron 45:651-660. CrossRef Medline

McGrath CL, Kelley ME, Holtzheimer PE, Dunlop BW, Craighead WE, Franco AR, Craddock RC, Mayberg HS (2013) Toward a neuroimaging treatment selection biomarker for major depressive disorder. JAMA Psychiatry 70:821-829. CrossRef Medline

McNally RJ (2007) Mechanisms of exposure therapy: how neuroscience can improve psychological treatments for anxiety disorders. Clin Psychol Rev 27:750-759. CrossRef Medline

Milad MR, Vidal-Gonzalez I, Quirk GJ (2004) Electrical stimulation of medial prefrontal cortex reduces conditioned fear in a temporally specific manner. Behav Neurosci 118:389-394. CrossRef Medline

Morilak DA, Fucich EA, Saunders M (2016) Modeling cognitive therapy in rats: fear extinction-induced infralimbic activity underlies reversal of 
chronic stress-induced shift towards passive coping. Soc Neurosci Abstr 42: Online Program 460.09.

Paxinos G, Watson C (2007) The rat brain in stereotaxic coordinates, Ed 6. San Diego, CA: Academic.

Quirk GJ, Garcia R, González-Lima F (2006) Prefrontal mechanisms in extinction of conditioned fear. Biol Psychiatry 60:337-343. CrossRef Medline

Ritchey M, Dolcos F, Eddington KM, Strauman TJ, Cabeza R (2011) Neural correlates of emotional processing in depression: changes with cognitive behavioral therapy and predictors of treatment response. J Psychiatr Res 45:577-587. CrossRef Medline

Rogers MA, Kasai K, Koji M, Fukuda R, Iwanami A, Nakagome K, Fukuda M, Kato N (2004) Executive and prefrontal dysfunction in unipolar depression: a review of neuropsychological and imaging evidence. Neurosci Res 50:1-11. CrossRef Medline

Salerian AJ, Altar CA (2012) The prefrontal cortex influence over subcorti$\mathrm{cal}$ and limbic regions governs antidepressant response by $\mathrm{N}=\mathrm{H} /(\mathrm{M}+$ R). Psychiatry Res 204:1-12. CrossRef Medline

Senn V, Wolff SB, Herry C, Grenier F, Ehrlich I, Gründemann J, Fadok JP, Müller C, Letzkus JJ, Lüthi A (2014) Long-range connectivity defines behavioral specificity of amygdala neurons. Neuron 81:428-437. CrossRef Medline

Shah AA, Sjovold T, Treit D (2004) Inactivation of the medial prefrontal cortex with the $\mathrm{GABA}_{\mathrm{A}}$ receptor agonist muscimol increases open-arm activity in the elevated plus-maze and attenuates shock-probe burying in rats. Brain Res 1028:112-115. CrossRef Medline

Sheline YI (2003) Neuroimaging studies of mood disorder effects on the brain. Biol Psychiatry 54:338-352. CrossRef Medline

Sierra-Mercado D, Padilla-Coreano N, Quirk GJ (2011) Dissociable roles of prelimbic and infralimbic cortices, ventral hippocampus, and basolateral amygdala in the expression and extinction of conditioned fear. Neuropsychopharmacology 36:529-538. CrossRef Medline
Sotres-Bayon F, Bush DE, LeDoux JE (2004) Emotional perseveration: an update on prefrontal-amygdala interactions in fear extinction. Learn Mem 11:525-535. CrossRef Medline

Straub J, Plener PL, Sproeber N, Sprenger L, Koelch MG, Groen G, Abler B (2015) Neural correlates of successful psychotherapy of depression in adolescents. J Affect Disord 183:239-246. CrossRef Medline

Treit D, Pesold C, Rotzinger S (1993) Dissociating the anti-fear effects of septal and amygdaloid lesions using two pharmacologically validated models of rat anxiety. Behav Neurosci 107:770-785. CrossRef Medline

Vertes RP (2004) Differential projections of the infralimbic and prelimbic cortex in the rat. Synapse 51:32-58. CrossRef Medline

Vidal-Gonzalez I, Vidal-Gonzalez B, Rauch SL, Quirk GJ (2006) Microstimulation reveals opposing influences of prelimbic and infralimbic cortex on the expression of conditioned fear. Learn Mem 13:728-733. CrossRef Medline

Warden MR, Selimbeyoglu A, Mirzabekov JJ, Lo M, Thompson KR, Kim SY, Adhikari A, Tye KM, Frank LM, Deisseroth K (2012) A prefrontal cortex-brainstem neuronal projection that controls response to behavioural challenge. Nature 492:428-432. CrossRef Medline

Wenzlaff RM, Wegner DM, Roper DW (1988) Depression and mental control: the resurgence of unwanted negative thoughts. J Pers Soc Psychol 55:882-892. CrossRef Medline

Yoshimura S, Okamoto Y, Onoda K, Matsunaga M, Okada G, Kunisato Y, Yoshino A, Ueda K, Suzuki S, Yamawaki S (2014) Cognitive behavioral therapy for depression changes medial prefrontal and ventral anterior cingulate cortex activity associated with self-referential processing. Soc Cogn Affect Neurosci 9:487-493. CrossRef Medline

Yuen EY, Wei J, Liu W, Zhong P, Li X, Yan Z (2012) Repeated stress causes cognitive impairment by suppressing glutamate receptor expression and function in prefrontal cortex. Neuron 73:962-977. CrossRef Medline 